\title{
Extra-Adrenal Glucocorticoid Synthesis in Mucosal Tissues and Its Implication in Mucosal Immune Homeostasis and Tumor Development
}

\author{
Feodora I. Kostadinova, Nina Hostettler, \\ Pamela Bianchi and Thomas Brunner
}

Additional information is available at the end of the chapter

http://dx.doi.org/10.5772/52788

\section{Introduction}

While glucocorticoids (GC) exert broad effects on metabolism, behavior and immunity, local production of even small amounts of GC, which may act in a paracrine or even autocrine manner, enable a specific site of the body to regulate their exposure to GC according to their specific needs. Mucosal tissues, for example, are at the borderline to the outside world, and are therefore in constant contact with either harmless foreign particles or potentially pathogenic microorganisms, which might provoke devastating inflammatory disorders due to chronic stimulation of the mucosal immune system. Increasing the local concentration of immunoregulatory GC by extra-adrenal de novo GC synthesis or local reactivation of inactive serum metabolites provides a protective mechanism to either restore homeostasis after clearance of infection or to regulate the critical balance between immunity and tolerance.

\section{Adrenal versus extra-adrenal GC synthesis}

Production of GC in the adrenal glands is regulated by hypothalamic-pituitary-adrenal (HPA) axis and follows under normal conditions the circadian rhythm. However, GC are also a major humoral response to various types of stress. [1]. Immunological stress by excessive activation of immune cells rapidly results in elevated plasma levels of tumor necrosis factor alpha (TNF $\alpha$ ), interleukin (IL) -1 and IL-6, which then stimulate the HPA axis and lead to an increase of systemic GC [2]. These and similar signals stimulate also the local GC synthesis in mucosal tissues, as will be discussed later (Table 1). 


\begin{tabular}{|c|c|c|c|c|}
\hline $\begin{array}{l}\text { Local GC } \\
\text { synthesis }\end{array}$ & Cellular source & Special features & Described functions & References \\
\hline Thymus & $\begin{array}{l}\text { Epithelial cells } \\
\text { in cortex }\end{array}$ & $\begin{array}{l}\text { Mutual } \\
\text { antagonism }\end{array}$ & Thymic selection & [3-7] \\
\hline $\begin{array}{l}\text { Skin } \\
\text { Hair follicle }\end{array}$ & $\begin{array}{l}\text { Keratinocytes, } \\
\text { melanocytes, } \\
\text { fibroblasts etc. }\end{array}$ & $\begin{array}{l}\text { Autonomous } \\
\text { HPA-axis }\end{array}$ & $\begin{array}{l}\text { Integrity and growth; } \\
\text { response to stress } \\
\text { factors }\end{array}$ & [8-19] \\
\hline $\begin{array}{l}\text { Cardiovascular } \\
\text { system }\end{array}$ & $\begin{array}{l}\text { Vessel walls, } \\
\text { Heart }\end{array}$ & $\begin{array}{l}\text { Together with } \\
\text { mineralocorticoids }\end{array}$ & $\begin{array}{l}\text { Vascular contractility } \\
\text { and remodeling }\end{array}$ & [20-29] \\
\hline $\begin{array}{l}\text { Central Nervous } \\
\text { system }\end{array}$ & Neurons, glia & $\begin{array}{l}\text { Various } \\
\text { neurosteroids }\end{array}$ & $\begin{array}{l}\text { Sensitizing GABA } \\
\text { and other receptors; } \\
\text { feed-back on HPA- } \\
\text { axis; cognitive } \\
\text { functions }\end{array}$ & [30-45] \\
\hline Intestine & Crypt cells & $\begin{array}{l}\text { Regulation via } \\
\text { LRH-1 }\end{array}$ & Immune regulation & {$[46-53]$} \\
\hline Lung & unknown & $\begin{array}{l}\text { Reactivation by } \\
11 \beta-H S D\end{array}$ & Immune regulation & {$[54]$} \\
\hline Colon carcinoma & Tumor cells & $\begin{array}{l}\text { Regulation via } \\
\text { LRH-1 }\end{array}$ & Immunosuppression & [55] \\
\hline
\end{tabular}

Table 1. Extra-adrenal GC sources and their functions.

Because most data published so far on local GC synthesis has been generated in animal models a brief overview of steroidogenic processes in rodents compared to humans must be made (Figure 1). A major difference is the implication of the enzyme $17 \alpha$-hydroxylase in the GC synthesis in humans, but not in rodents. Pregnenolone is transformed directly into progesterone in most rodents, and in other mammalians and humans it is first hydroxylated and then metabolized into 17-OH-progesterone [56]. 11 $\beta$-hydroxylase (P450C11) is an enzyme expressed in the zonae fasciculata et reticularis and is a product of the gene CYP11B1. Thus, in rodents this enzyme uses 11-deoxycorticosterone as a substrate and turns it into corticosterone, which is the active GC in these species. In humans $11 \beta$-hydroxylase metabolizes mainly 11-deoxycortisol into cortisol and to a lesser degree 11deoxycorticosterone into corticosterone. Hence, cortisol is the major active GC in the human. 11-Deoxyorticosterone and corticosterone are important metabolites in both species, which can be hydroxylised and oxidised in the zona glomerulosa of the adrenals, subsequently leading to the mineralcorticosteroid aldosterone [57].

It is well established that the adrenal glands are the major source of systemic GC. Surgical removal of the adrenal glands results in a rapid drop of serum GC levels, which after a couple of days become undetectable, illustrating that the adrenals are primarily responsible for the GC levels detected in the circulation $[46,58]$. However, in recent years there has been 
accumulating evidence that several other tissues are capable of producing GC and thereby regulate local processes in an adrenal-independent manner $[7,59]$.

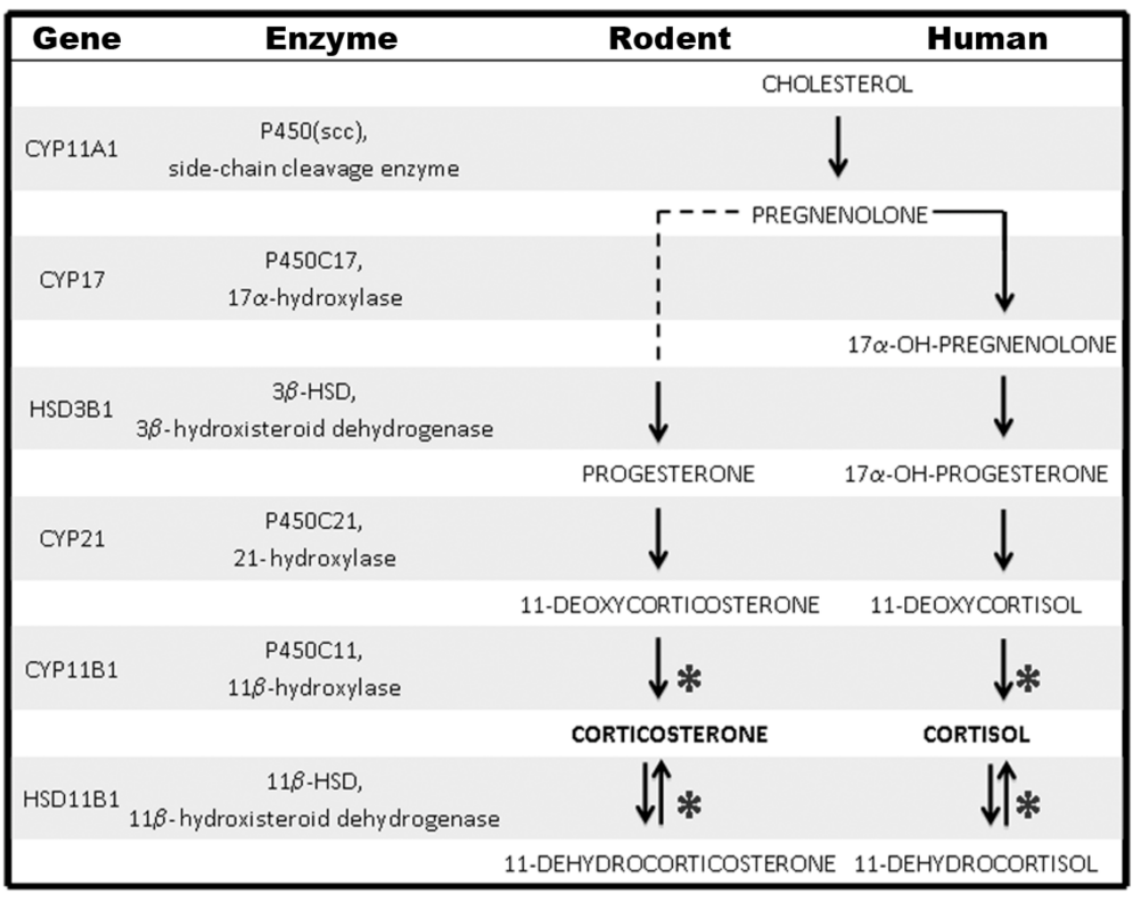

Legend: enzymes; $\square$ metabolites: $\rightarrow$ metabolic pathway; - - - absent in rodents; ${ }^{*}$ inhibitory effect of metyrapone.

Figure 1. Differences in the GC synthesis pathway in rodents and humans.

\section{Extra-adrenal sources of GC synthesis}

\subsection{Thymus}

The Thymus plays a central role in the development of the immune system. Thymocyte development and differentiation is shaped and regulated by the interaction with the thymic epithelial cells and the factors secreted by them $[60,61]$.

Initial characterizations of extra-adrenal GC synthesis started in the thymus. In the mid to late 90ties of the last century it was described that the non-immune cells in the thymic cortex are capable of producing various steroid metabolites. Accordingly, the expression of various enzymes of the corticosteroid synthesis pathway has been demonstrated in thymic epithelial cells [3-5]. While the function of thymic GC has been a matter of scientific debate for some time [62, 63], particularly the work of Ashwell and co-workers illustrated that GC production in the thymus has an important role in the regulation of thymocyte development and selection. Interestingly, while thymocytes are exquisitely sensitive to GC and rapidly die by apoptosis, the in situ produced corticosterone seems to oppose the signals induced by 
the $\mathrm{T}$ cell receptor and thereby lower $\mathrm{T}$ cell receptor-induced apoptosis (negative selection). On the other hand $\mathrm{T}$ cell receptor activation also inhibits the apoptosis-inducing activity of GC in thymocytes [64]. Thus, the "mutual antagonism" between T cell receptor and glucocorticoid receptor (GR) signaling seems overall to enhance survival and thereby positive selection of thymocytes by increasing the threshold of $\mathrm{T}$ cell receptor signals leading to negative selection [3]. The thymus in mice produces the highest amounts of GC during fetal development and in the first weeks after birth. This is the time of the most extensive lymphocyte development and differentiation, and it occurs at a time when the steroidogenesis in the adrenals is not fully active. Thus, the thymus seems to depend largely on its own by providing the necessary GC. Whether thymic epithelial cells constitutively produce GC or whether this is dependent on the interaction with activated thymocytes or soluble factors, is presently unknown. The presence or absence of factors regulating thymic GC synthesis may, however, affect positive and negative selection of thymocytes, and thereby also affect the levels of potentially autoreactive T cells in the periphery. [6, 7].

\subsection{Skin}

The skin is an organ with a complex structure and its purpose is to protect the inner organism from the environmental factors, infections, dehydration, thermal deregulations etc. The outer cover of the skin, the epidermis, maintains its integrity through intense selfrenewing by the proliferating keratinocytes in the basal layer and the dividing cells in the hair follicles. As such skin is an important component of the defense mechanisms providing not only a reliable mechanical barrier and producing antimicrobial enzymes and other substances, but also being populated with many specialized immune cells, e.g. dendritic cells (Langerhans cells) within the epidermis, as well as resident macrophages, dendritic cells and lymphocytes in the derma [65]. The skin also displays active metabolic and endocrine functions. Along with the synthesis of vitamin D, the skin was shown to produce various hormones and regulatory factors, like parathyroid-related protein, melanocytestimulating hormone (MSH), $\beta$-endorphin peptides, urocortin, neurotransmitters and others (for review $[10,11]$ ). With regard of this chapter's topic of interest is the ability of the skin to produce all components of the HPA axis. A great contribution to the understanding of GC metabolism and regulation in the skin has been made by the extensive research of Slominski and co-workers [10]. In human keratinocytes and cells of the hair follicles expression of corticotropin-releasing factor (CRF) has been demonstrated at the mRNA and protein level, whereas in mice the local synthesis of CRF has not been proven yet. The observed local increased concentration of CRF in the skin could be possibly explained by its release from neuronal cells and its active transport into the skin along the local nerve endings [12, 15]. Many cell types found in the skin, e.g. keratinocytes [66], melanocytes [13], dermal fibroblasts [67], immune cells and endothelial cells in the derma, as well as hair follicles [16] and skin tissue cultures, are able to respond to CRF stimulation and to produce proopiomelanocortin, which can be further processed into adrenocorticotropic hormone (ACTH), MSH and $\beta$-endorphin. Moreover, GC-synthesizing enzymes and active GC have been demonstrated in human and rodent skin. Metabolic assays demonstrated that ex vivo cultured normal rat skin could transform progesterone into deoxycorticosterone and 
corticosterone, and further to 11-dehydrocorticosterone [9]. Human skin has been demonstrated to respond to $\mathrm{ACTH}$, to express various steroidogenic enzymes, and to be capable of synthesizing cortisol $[8,18]$. Local steroidogenesis was demonstrated in human keratinocytes [19], sebaceous cells [18], fibroblasts [14], and melanocytes [13]. Hair follicles, also known as pilosebaceus units, appear to function as fully autonomous peripheral equivalents of the HPA axis. The CRF/ACTH-induced cortisol production appears to provide also a negative feedback on the local CRF synthesis and thereby terminate local steroidogenesis [15]. It has been suggested that this local HPA axis is implemented in the regulation of hair growth, pigmentation and modulation of local immune response [17]. Components of the HPA axis, mainly CRF, are proposed to affect the epithelial cell proliferation, apoptosis and differentiation [15]. Recent findings describe the role of local cortisol synthesis in a model of tissue injury. Up-regulation of CYP11B1 and subsequent enhanced production of cortisol was induced by the proinflammatory cytokine IL-1 $\beta$ and depressed by insulin-like growth factor 1 (IGF-1) [19]. In the same study elevation of cortisol synthesis was observed approximately 48 hours after acute injury and maintained the proper wound healing.

In conclusion, the skin possesses an autonomous HPA axis, regulating the normal integrity and growth, and is able to respond to stress factors. At the same time the GC-synthesizing machinery of the skin can be stimulated by inflammatory mediators in order to provide an adequate local self-limitation of immune responses.

\subsection{Central nervous system}

The term neurosteroids was defined after the discovery that various steroid metabolites can be detected in the brain of simultaneously adrenalectomized and gonadectomized rats [30]. Among the locally synthesized and active steroids are pregnenolone and pregnenolone sulphate, progesterone, allopregnanolone, dehydroepiandrosterone and dehydroepiandrosterone sulphate. These steroids can exert their effects in neurogenesis, development, myelinization, memory, reactions to stress through engaging nuclear receptors and modulating transcription, as well as affecting neurotransmission by modifying the activity of gamma-aminobutiric acid (GABAA), N-methyl-D-aspartic acid (NMDA), and sigma receptors (for review [31, 32, 68]). Low levels of transcripts for CYP11A1, CYP11B1 and the other enzymes of corticosterone synthesis were detected in normal rat brain, in cerebral cortex and cerebellum [33], and 11 $\beta$-hydroxylase protein expression was later demonstrated in the Purkinje cells and other cells of the hippocampus [35]. In vitro conversion of precursors into corticosterone has also been demonstrated in rat fetal hippocampal neurons [34]. The extremely low levels of CYP21 transcripts and enzyme (deoxycorticosterone synthetase, P450C21) detected [36] gave raise to many doubts whether complete GC synthesis can be sustained in the brain. Nevertheless, the activity of brain tissue to convert progesterone to 11-deoxycorticosterone (resp. $17 \alpha-\mathrm{OH}$-progesterone to 11deoxycortisol) pointed out that steroid metabolism in the brain exists. Recently, the expression of isoforms of CYP2D4 and CYP2D6 in rat and human brains, respectively, as well as demonstration of their 21-hydroxylation activity confirmed the capacity of rodent 
and human brain to produce GC locally [37, 69], though suggesting a slightly different enzymatic pathway compared to that of the adrenals. Nonetheless, CRF and ACTH, likely released by the hypothalamus, resp. pituitary gland, seem to regulate GC synthesis in the brain in a similar manner as in the adrenals. Interestingly, adrenalectomy even increases the expression of CYP11B1 in the rat brain [70].

Peripheral reactivation of 11-dehydrocorticosterone to corticosterone, resp. cortisone to

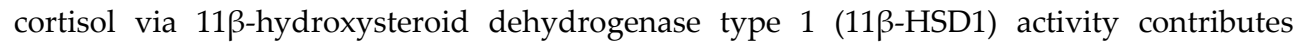
considerably not only to the local concentrations and effects of GC, but also to the plasma level of GC, as shown by an almost 30\% increase in corticosterone levels in the portal vein compared to the incoming arterial circulation [38, 39, 71]. In the brain $11 \beta-H S D 1$ expression was found in various areas. Local levels of corticosterone in the cerebral cortex, hippocampus, hypothalamus and pituitary gland modulate the activity of the HPA axis. This effect is particularly apparent in $11 \beta$-HSD1 knockout mice. The lack of $11 \beta$-HSD1 activity in the brain of these mice leads to considerably reduced local levels of corticosterone. Hence, the HPA axis is hyperactivated and higher amounts of ACTH are produced, which in turn causes adrenal hypertrophy. Normal or even elevated systemic GC fail to transmit proper feedback responses to the hypothalamus [40-42]. Other curious effects of the local levels of GC attributed to the activity of $11 \beta$-HSD1 in the hippocampus are cognitive disorders during aging. Experiments in 11 $\beta$-HSD1-deficient mice showed that these animals are protected from the decline of the learning abilities [43, 72]. 11 $\beta$ HSD1 is expressed in the human prefrontal cortex, cerebellum and hippocampus, and its expression, as well as local GC levels, has also been correlated to the cognitive decline in elderly patients [44, 45], [42]. Furthermore, some clinical studies showed an improvement

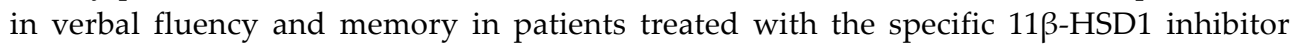
carbenoxolone [44].

\subsection{Cardiovascular system}

The impact of mineralocorticoids and glucocorticoids on the heart and blood vessels is well known and described. Yet, the capacity of these structures to sustain their own supplies is not understood in detail. Data obtained mainly in rats indicate that vascular tissue expresses steroidogenic factors, such as StAR, CYP11A1, CYP11B1 and CYP11B2 [20, 21, 73]. Ex vivo cultured rat blood vessels were able to produce corticosterone and aldosterone [23, 73]. Expression of various steroidogenic enzymes has been shown also in the human heart and blood vessels [26, 27]. However, CYP11B1 and CYP11B2 expression was only demonstrated in patients with myocardial infarction and heart failure [28], but barely under steady state conditions or in cultured endothelial cells [29], suggesting that local GC synthesis may be triggered during pathological conditions. Presence of CYP11B2 (aldosterone synthetase) and the fact that steroidogenesis in the cardiovascular system is triggered by the angiotensin signaling system [24] points out that local steroidogensis in the vascular systems is connected to the renin-angiotensin-aldosterone regulatory mechanisms [25]. Local reactivation of 11-dehydrocorticosterone was also observed in the smooth muscle cells in arteries, where it may contribute to vascular contractility and remodeling [74], [75]. Despite 
a clear demonstration of steroidogenesis in the vasculature detailed studies on the antiinflammatory role of local GC synthesis in blood vessels are still missing.

In addition to the different tissues described above local GC synthesis was also reported in the placenta [76], the ovaries [77], the testis [78], the uterus [79], and the mammary gland [80].

\section{GC synthesis in mucosal tissues}

Mucosal surfaces in the gastrointestinal, respiratory and urinal tract represent important contact zones between the body and the outside world. They exert important functions in the exchange of nutrients, gases and other substances between the organism and the surrounding world. They comprise an enormous interactive surface and are thereby also constantly exposed to various antigens and microorganisms. Though, most of them are harmless, and thus the body has developed mechanisms to tolerate these harmless antigens. Yet, dangerous infections of the lung and the intestine occur, in which case the local defense machinery must be engaged to protect the host from invasion. The barrier between inside and outside is primarily formed of a simple one-layered epithelium with the respective specialized functions. Beneath the epithelial layer in the lamina propria of the intestine or in the interstitium of the lung resides a large number of immune cells. Clearly the huge mucosal surface must be protected from invading pathogens, and thus these epithelial tissues are home of the largest immune system in our body. Inappropriate activation of these local immune cells by environmental antigens, though, can result in uncontrolled inflammation and associated tissue destruction. Several lines of evidence discussed in detail below indicate that locally produced GC significantly contribute to the regulation of local immune responses and the maintenance of immune homeostasis in these epithelial tissues.

\subsection{GC synthesis in the intestinal epithelium}

In the intestinal mucosa two super-systems collide. The intestinal lumen hosts ten times more bacteria than cells in our body are found. At the same time, the intestinal epithelium and lamina propria are also home of the largest number of $\mathrm{B}$ and $\mathrm{T}$ cells, and are also densely populated by macrophages and dendritic cells. Accidental and uncontrolled activation of these cells and/or other infiltrating immune cells by harmless commensal bacteria or food antigens is the underlying cause of a variety of inflammatory disorders, such as inflammatory bowel disease and food allergies [81]

There is accumulating evidence that local production of immunoregulatory GC significantly contributes to the control of intestinal immune homeostasis and prevents a clash between immune cells and commensal bacteria. The notion that the intestinal mucosa could be a steroidogenic organ has been already suggested some time ago, when it was found that genetic deletion of the nuclear receptor SF-1 (steroidogenic factor-1, NR5a1), largely responsible for the transcriptional control of the adrenal development and GC synthesis, could not abrogate intestinal CYP11A1 expression in the mouse embryonic gut [82]. At the same time remaining GC levels were observed in the circulation of prenatal mice, indicating that an extra-adrenal source of GC synthesis must exist [83]. Our own research started to explicitly 
investigate the possibility that the intestinal mucosa is an important source of immunoregulatory GC some ten years ago. Investigating the function of so-called intraepithelial lymphocytes, T cells that reside within the intestinal epithelial layer, it was found that these cells rapidly died upon isolation and ex vivo culture, but could be partially rescued when the GR was blocked by the receptor antagonist RU-486 [84]. This observation suggested that these intestinal T cells were constantly exposed to GC, and that removal of survival signals, e.g. by detachment from the epithelial layer, would promote GR-dependent apoptosis.

Subsequent studies revealed that the intestinal mucosa is home of a complex steroidogenic system, likely adapted to cope with the specialized environment of the gut. Many of the steroidogenic enzymes required for the synthesis of corticosterone from cholesterol or the reactivation of corticosterone from dehydrocorticosterone are constitutively expressed in the intestinal epithelium, whereas other enzymes become strongly induced upon immunological stress [46, 52, 53]. The ability of the intestinal tissue to synthesize corticosterone in mice [46] and humans [55] indicates that the intestinal mucosa expresses the complete and functional enzymatic machinery. This steroidogenic capacity is further confirmed by the use of metyrapone, a potent 11 $\beta$-hydroxylase inhibitor with some inhibitory effects also on P450scc and 11 $\beta$-HSD1, which efficiently blocks ex vivo GC synthesis in intestinal organ cultures $[46,55]$, confirming that GC measured were produced locally in the tissue.

While in most experiments and ex vivo organ cultures basal GC levels are detected, a significant induction is usually observed, when mice are stressed by immune cell-activating agents. Administration of $\mathrm{T}$ cell-activating anti-CD3 $\varepsilon$ antibody, macrophage-activating lipopolysaccharides, or $\mathrm{TNF} \alpha$, infection of mice with viruses or chemically induced intestinal inflammation promotes the expression of certain steroidogenic enzymes, e.g. CYP11A1 and CYP11B1, and strongly stimulates the synthesis of intestinal GC. In some of these in vivo experiments a role of intestinal GC synthesis in the control of intestinal immune cells could also be confirmed. Most pronounced are the effects reported on viral infection and experimental colitis. Infection of mice with the lymphocytic choriomeningitis virus (LCMV) leads to a rapid expansion of the virus, which infects various target organs, including the intestine $[46,85,86]$. The virus promotes a massive expansion of virus-specific cytotoxic $\mathrm{T}$ cells, which in turn control the viral expansion by killing virus-infected cells. Employing this experimental system it has been shown that intestinal T cells from mice with deregulated intestinal GC synthesis (using the pharmacological inhibitor of GC synthesis metyrapone) became more profoundly activated by the virus, and expressed activation markers and inflammatory cytokines at much higher levels [46]. Similarly, in experimental models of colitis defective intestinal GC synthesis resulted in a more rapid and more pronounced induction of intestinal inflammation, as monitored by immune cell infiltration, epithelial layer damage, weight loss, etc. [49, 53].

\subsection{Regulation of intestinal GC synthesis}

The regulation of adrenal GC synthesis has been well documented over many decades of research (reviewed in [87]). The connection between physical, emotional and immunological 
stress, and the activation of the HPA axis has been well established. Similarly, the role of the hormone ACTH in stimulating adrenal GC synthesis, and the nuclear receptor SF-1 in the transcriptional control of adrenal steroidogenesis is widely accepted [88]. In agreement with this critical role of SF-1 in the induction of steroidogenic enzymes in the adrenal glands is the observation that mice deficient for SF-1 have no detectable corticosterone in the serum. In fact, SF-1-deficient mice even lack adrenal glands, as SF-1 is also required for the embryonic development of the adrenal glands. As discussed above, mice lacking SF-1 expression still express the steroidogenic enzyme gene CYP11A1 in the primitive gut of embryonic mice, supporting the notion that in the intestine steroidogensis is differentially controlled. Along these lines, it was found that SF-1 expression is basically absent in the intestine, but functionally replaced by its close homolog LRH-1 (liver receptor homolog-1, NR5a2). LRH-1 has strong sequence homology with SF-1, and regulates gene expression by binding to identical transcription factor response elements in the promoter of their target genes [47]. In general, SF-1 and LRH-1 have a mutually exclusive expression pattern, with very low LRH-1 expression in the adrenals, but very high expression in epithelial cells from the liver, pancreas, intestine and ovaries [89].

The role of LRH-1 in the regulation of extra-adrenal GC synthesis in the intestine has been investigated in intestinal epithelial cell lines in vitro as well as in vivo models [47, 49]. Overexpression of LRH-1 in intestinal epithelial cells induces the expression of the steroidogenic enzymes CYP11A1 and CYP11B1, and mutation of corresponding response elements in their promoter abrogates their LRH-1- and SF-1-induced activation [47]. Similarly, inhibition of LRH-1 expression or function leads to reduced expression of these steroidogenic enzymes in intestinal epithelial cells. Overexpression of LRH-1 in turn directly promotes detectable levels of corticosterone in the supernatant of intestinal epithelial cell cultures. In vivo the role of LRH-1 has been investigated by the use of LRH-1 haplodeficient as well as conditional LRH-1 knockout mice [48, 49]. LRH-1 haplodeficient mice showed a largely reduced induction of steroidogenic enzymes after anti-CD3 $\varepsilon$ injection and a complete block in intestinal GC synthesis induction, confirming an important role of LRH-1 in the regulation of intestinal GC synthesis. While induction of DSS (dextran sodium sulfate)- or TNBS (trinitrobenzen sulfonic acid)-mediated colitis stimulates the expression of steroidogenic enzmymes and a transient intestinal GC synthesis [51], deletion of LRH-1 in intestinal epithelial cells largely abrogates intestinal steroidogenesis [49]. More importantly, absence of LRH-1 and associated intestinal GC synthesis also leads to a more pronounced and accelerated colitis, confirming an important role of LRH-1 and intestinal GC synthesis in the regulation of local immune responses. LRH-1 likely regulates intestinal GC synthesis not only via the induction of certain steroidogenic enzymes. Steroid acute regulator (StAR) has an important role in transporting cholesterol within the cell, and thus supplying the steroid synthesizing machinery with the substrate for GC synthesis. As LRH-1 also transcriptionally regulates StAR expression [90], LRH-1 seems to control intestinal GC synthesis at many levels.

Interestingly, LRH-1 appears to have various modes of activation. Though initially defined as orphan nuclear receptor due the lack of known ligands, the crystallization of 
LRH-1 and subsequent structural analysis revealed a ligand binding to the ligand-binding domain of LRH-1. This ligand was identified as phosphatidylinositol, however, it is very likely that a larger variety of natural and synthetic ligands may bind to this ligandbinding domain and transactivate LRH-1. Of interest are recent reports demonstrating LRH-1 activation by testosterone [91], the herbizide atrazin [92] as well as several synthetic ligands with selective activities for LRH-1 over SF-1 [93]. However, ligand binding may not be an absolute requirement for LRH-1 activation. In particular, mouse LRH-1 can be activated in a ligand-independent manner, as mutation of the ligandbinding domain does not affect its activity [94].

In marked contrast, phosphorylation by upstream kinases may selectively activate both, human and mouse LRH-1. Two serine residues in the hinge region of LRH-1 have been identified as phosphorylation targets of the MAP kinase ERK1/2, and mutation of these two serine residues strongly affects LRH-1 activity [95]. In line with this idea of LRH-1 activation via the MAP kinase pathway is the observation that the MEK1 inhibitor U0126 also blocks LRH-1 activity ([95]; Bianchi, Brunner, unpublished). Next to ERK1/2 also other yet to be identified kinases may be involved in LRH-1 phosphorylation and activation.

As many other nuclear receptors LRH-1 is also efficiently regulated by cofactors and repressors. For example, SRC-1 (steroid receptor coactivator-1) binds to LRH-1 and enhances its transcriptional activity. On the other hand, various inhibitors of LRH-1, such as DAX-1 (dosage-sensitive sex reversal, adrenal hypoplasia critical region, on chromosome $\mathrm{X}$, gene 1), SHP (small heterodimer partner) and Prox-1 (Prospero homeobox protein 1) have been shown to interact with LRH-1 and inhibit its activity $[89,96,97]$. Of interest is the fact that SHP is a major transcriptional target of LRH-1, and SHP induction likely represents a negative feedback loop terminating the transcriptional activity of LRH-1.

Thus far intestinal GC synthesis has been always described in the context of immunological stress and inflammation. Clearly, factors released by activated immune cells must be able to trigger steroidogenesis in intestinal epithelial cells, likely via the activation of LRH-1. Of major interest in this regard are factors that also promote adrenal GC synthesis. Surprisingly, ACTH or ACTH receptor signaling pathways, such as an increase in cellular cyclic AMP, fail to promote intestinal GC synthesis and rather inhibit it [47] indicating that next to the preferential use of SF-1 and LRH-1 there are other elements in the regulation of adrenal versus intestinal GC synthesis that are different. The pro-inflammatory cytokines IL-6 and TNF $\alpha$ are known as potent triggers of adrenal GC synthesis. While no evidence could be found for a role of IL- 6 in the immune cell-mediated induction of intestinal steroid synthesis, TNF $\alpha$ appears to represent a critical mediator of intestinal GC synthesis. TNF $\alpha$ alone promotes the expression of steroidogenic enzymes in intestinal epithelial cells in vitro and in vivo, and stimulates the synthesis of corticosterone. More importantly, induction of intestinal GC synthesis by injection of anti-CD3e, LPS as well as experimental colitis largely depends on the signaling via TNF receptors [53]. Surprisingly, deletion of either one of the two TNF receptors abrogates immune cell-induced intestinal GC synthesis [52], indicating that simultaneous signaling via both receptors is required. 
The important role of $\mathrm{TNF} \alpha$ in the induction of intestinal GC synthesis is particularly evident when analyzing different models of experimentally induced colitis. While DSS and the hapten TNBS promote intestinal steroidogenesis, the hapten oxazolone fails to do so, despite very comparable induction of inflammation [53]. Clearly, inflammation alone is insufficient to initiate intestinal steroidogensis, but the type of inflammation may be critical. DSS and TNBS stimulate an immune response with Th1 cytokine predominance, abundant TNF $\alpha$ and IFN $\gamma$, whereas oxazolone promotes a Th2 type cytokine response with no TNF $\alpha$, but IL-4 and IL-5. Supporting the important role of TNF $\alpha$ in these processes, it was found that oxazolone does not trigger intestinal GC synthesis, however injection of recombinant TNF $\alpha$ can restore the expression of steroidogenic enzymes and GC synthesis, and thereby ameliorate intestinal inflammation induced by oxazolone. Thus, TNF $\alpha$ seems to be an important sensor of immunological stress in the intestine and responsible for initiating negative feedback mechanisms via the induction of intestinal GC synthesis. This is inasmuch surprising as $\mathrm{TNF} \alpha$ is an important therapeutic target in the pathogenesis of inflammatory bowel disease (IBD), such as Crohn's disease and ulcerative colitis [98-100]. TNF $\alpha$ is an important disease promoting and initiating factor during IBD, and its neutralization inhibits inflammatory processes right from the start. Its role in the regulation of intestinal GC synthesis, however, point also out a thus far unrecognized antiinflammatory role of $\mathrm{TNF} \alpha$ (reviewed in [51]).

\subsection{GC synthesis in the lung}

The intestinal and the lung epithelium have much in common. Their main function is the absorption of nutrients and gases, respectively, and due to their enormous surface to cope with this task they are also constantly exposed to a plethora of antigens, microbes and potential pathogens. Thus, much alike the intestinal mucosa the lung harbors a large number of resident immune cells, mostly macrophages and dendritic cells, and is rapidly populated by infiltrating immune cells upon infection or stimulation with antigens. Similarly, uncontrolled immune responses in the lung may lead to chronic disorders, such as allergen-induced asthma and chronic obstructive pulmonary disorder (COPD). This illustrates on one hand the need for an efficient immune response in the lung in order to defend this vast epithelial surface from infection and invasion by pathogens, but also points out that local immune responses must be tightly regulated to avoid chronic inflammation, tissue damage and resulting loss of function of the absorptive epithelium.

All these thoughts suggest that similar regulatory mechanisms exist in the lung as in the intestinal mucosa, and local GC synthesis may represent such a homeostatic control mechanism. Indeed, it has been described that genes involved in the GC synthesis pathway are transiently expressed in the developing mouse lung [101]. More recently, our own research has investigated the capacity of the adult lung to express steroidogenic enzymes and to synthesize GC in response to immunological stress [54]. Unlike the intestinal epithelium, the entire enzymatic machinery appears to be constitutively expressed in the adult lung tissue, and only CYP11A1, encoding P450scc, is induced upon immunological stress initiated by injection of $\mathrm{T}$ cell-activating anti-CD3 $\varepsilon$ antibody or macrophage-activating 
LPS. Furthermore, particularly CYP11B1, although detectable by quantitative PCR, seems to be expressed at very low levels and not to be induced as in the intestine. When analyzing corticosterone synthesis in ex vivo lung cultures two observations are compelling. The lung tissue constitutively synthesizes considerable amounts of corticosterone in unchallenged mice, and the induced GC levels upon immunological stress are much higher when compared to equal amounts of tissue in the intestine [54]. Importantly, also in the lung ex vivo GC synthesis is efficiently blocked by the pharmacological inhibitor metyrapone, supporting the idea that GC measured are de novo synthesized in the lung tissue, though here its effect may not be via the inhibition of $11 \beta$-hydroxylase. This indicates that the lung tissue may be an even more potent extra-adrenal source of immunoregulatory GC than the intestinal epithelium.

Thus far, the cellular source of lung GC synthesis has not been identified yet. Very likely, though, lung epithelial cells, either type I or type II epithelial cells, may be the relevant source of lung GC. In support of this hypothesis is the observation that lung epithelial cell lines express steroidogenic enzymes and are capable of metabolizing steroid precursors to corticosterone (Hostettler, Brunner, unpublished observations). Despite the many similarities between the intestinal and the lung epithelium in terms of response to inflammatory triggers and the synthesis of GC, there are also many differences in the induction of intestinal versus lung GC synthesis. While systemic activation of immune cells by anti-CD3 or LPS injection triggers both, intestinal and lung GC synthesis [52, 54], the response to local inflammation seems to be regulated somewhat differently. A typical model of allergic airway inflammation is the sensitization of mice with the model antigen ovalbumin in the context of alum as adjuvant, and the challenge with the antigen via aerosol. This leads to a $\mathrm{T}$ helper 2 type inflammatory response with a major eosinophilic and neutrophilic granulocyte infiltration of the lung tissue and lung lumen within 24 hours. Despite the massive inflammation and infiltration with immune cells only a minimal and not significant transient increase in local GC synthesis is observed, not comparable to the high concentrations measured after stimulation with anti-CD3 or LPS [54]. Given the fact that ovalbumin airway hypersensitivity and oxazolone-induced colitis are both T helper 2driven immune responses, the idea that lack of $\mathrm{TNF} \alpha$ secretion could be the missing stimulator of lung GC synthesis appears very attractive. Indeed, only minimal TNF $\alpha$ levels are measured in the serum and the bronchoalveolar lavage (BAL) after ovalbumin challenge [54]. Similarly, when TNF $\alpha$ is injected into mice local GC synthesis in the lung can be efficiently induced. However, experiments in TNF receptor-deficient mice using anti-CD3 as a trigger clearly showed that TNF $\alpha$ signaling is not required for immune cell-stimulated local GC synthesis in the lung tissue. Thus, very likely other cytokines and/or factors, yet to be identified, may be substituting TNF $\alpha$ as a sensor of immune cell activation and trigger of local GC synthesis. It is feasible to believe that such a sensor of immunological stress is not induced during allergic inflammation of the lung, e.g. asthma, but present during contact with pathogens, such as influenza infection, thereby helping to reestablish local immune homeostasis via the secretion of GC. The identification of this or these critical inducers of local GC synthesis may lead to interesting targets for therapeutic intervention of chronic inflammation of the lung via the induction of local GC synthesis. 


\subsection{Regulation of lung GC synthesis}

Presently, not much is know regarding the molecular mechanisms of lung GC synthesis, and more detailed analysis of the regulatory pathways leading to the induction and activation of steroidogenic enzymes in the lung tissue will be needed. While the presence of all steroidogenic enzymes required for the synthesis of corticosterone from cholesterol suggests identical synthesis pathways in the lung, adrenals and intestine, metabolic assays indicate major differences between the tissues. Interestingly, ex vivo cultured lung tissue failed to convert radioactively labeled deoxycorticosterone into corticosterone, suggesting that the expression levels of CYP11B1/11 $\beta$-hydroxylase are insufficient to promote this pathway of GC synthesis. In contrast, dehydrocorticosterone is efficiently metabolized by the lung tissue into corticosterone, supporting the idea that reactivation of inactive serum dehydrocorticosterone via an $11 \beta$-HDS1-dependent pathway is the primary corticosterone synthesis pathway in the lung. Along these lines is the observation that the lung expresses very low levels of CYP11B1 but very high levels of HSD11B1, and that adrenalectomy completely abolishes lung GC synthesis [54]. Though metyrapone has been reported to be selective for $11 \beta$-hydroxylase, inhibition of $11 \beta$-HSD1 has also been noted [102], explaining why ex vivo GC synthesis in lung tissue is efficiently blocked by metyrapone. A dominant role for an 11 $\beta$-HSD1-dependent corticosterone synthesis pathway is also supported by the lack of evidence for a role of LRH-1 in the regulation of lung GC synthesis. While anti-CD3induced intestinal GC synthesis was significantly reduced in LRH-1 haplodeficient mice [48], lung GC synthesis was found to be normal [54], indicating that other nuclear receptors or transcription factors are involved in the regulation of steroidogenesis in the lung tissue.

\section{GC synthesis in colorectal tumors}

The role of tumor immunology in the surveillance of transformed cells and the control of tumor development is a highly controversial issue. While tumor-specific immune responses and even tumor-specific $\mathrm{T}$ cells can be demonstrated in certain types of tumors, stimulation of tumor-specific $\mathrm{T}$ cells by immunization has thus far not been too successful in the prevention or treatment of tumors. A major exception is the vaccination against human papilloma virus, which strongly reduces the incidence of cervical cancer [103, 104]. Despite relatively disappointing results of such immunization protocols, clinical and histological studies support the notion that tumor-infiltrating leukocytes (TIL) are indeed capable of limiting the growth and development of certain types of cancer. An extensive study in patients with colorectal cancer revealed that those patients that had a pronounced infiltration of the tumor with lymphocytes, and in particular with memory $\mathrm{T}$ cells, showed a significantly prolonged survival compared to patients with little or no immune cell infiltrate [105]. Though an indirect proof, these studies demonstrate a strong correlation between anti-tumor immune responses, tumor development and patient survival. These findings, however, also suggest that tumors capable of escaping or suppressing immune responses by any means may have a major advantage and kill the patient more rapidly. 
Various immune escape mechanisms have been described in different tumors. Tumor cells secrete suppressive cytokines, such as TGF $\beta$ and IL-10, express pro-apoptotic ligands (Fas ligand and TRAIL), which kill TIL, or simply reduce their immunogenicity by downregulating MHC molecules and associated antigen presentation on their surface. In this paragraph we will also discuss the proposed role of extra-adrenal GC synthesis in colorectal tumors as a mechanism of immune escape. Though various types of tumors have been shown to be active sources of steroid hormones, most of these tumors derive from steroidogenic tissues, such as the adrenal glands, ovaries or testis. For example, adrenal hyperplasia and tumors often lead to a massive release of GC, resulting in Cushing syndrome [106]. In addition, small cell bronchogenic carcinoma, carcinoids of thymus, pancreas, ovary, as well as medullary carcinoma of thyroid gland etc. have been shown to release ACTH or in rare cases $\mathrm{CRH}$, and thereby to stimulate indirectly the release of systemic GC from the adrenals with subsequent suppression of the immune system [107, 108]. Yet, thus far no direct GC synthesis in tumors from non-steroidogenic tissues has been described.

As discussed in detail above, LRH-1 has a prominent role in the regulation of intestinal GC synthesis [48, 52]. Interestingly, however, LRH-1 has also been implicated in other aspects of intestinal epithelial cell biology. LRH-1 is primarily expressed in the pluripotent and proliferating cells of the intestinal crypts where it regulates the expression of cyclin D1. Furthermore, in collaboration with the Wnt signaling pathway and $\beta$-catenin it also controls the expression of cyclin E1 and c-Myc, and thereby the proliferation of crypt cells and the renewal of the intestinal epithelial layer (reviewed in $[109,110])$. Not surprisingly, this mitogenic role of LRH-1 appears to be also involved in the development of intestinal tumors. Mice with a mutation in the APC gene (APC ${ }^{\mathrm{min} /+}$ mice) spontaneously develop adenomas in both small and large bowel. Interestingly tumor development is significantly reduced in mice with LRH-1 deficiency [111]. Thus, LRH-1 appears to be a proto-oncogene in the development of intestinal tumors. In line with this idea is the observation that different tumors derived from endoderm tissue show LRH-1 overexpression. For example, LRH-1 is overexpressed in colorectal [55] and in pancreatic tumors [112], where it also regulates cell cycle progression.

Given the important role of LRH-1 in cell cycle regulation as well as intestinal GC synthesis LRH-1-mediated synthesis of immunoregulatory GC in colorectal tumors as a mechanism to control anti-tumor immune responses appears to be an attractive idea. Indeed, considerable synthesis of cortisol can be measured in colorectal cancer cell lines as well as primary colorectal tumors using radioimmuno assay, bioassay as well as metabolic assays [55]. In line with this steroidogenic potential of colorectal tumor cells is the widely distributed expression of LRH-1 and steroidogenic enzymes. Furthermore, overexpression of LRH-1 further boost the expression of steroidogenic enyzmes and the synthesis of cortisol, whereas inhibition of LRH-1 expression downregulates these processes. Interestingly, GC synthesis in colorectal tumor cell lines as well as ex vivo cultured primary tumors seems to be constitutive, whereas in normal colonic tissue it is inducible by phorbol ester, likely via the ERK1/2-mediated activation of LRH-1. This suggests that in colorectal tumors LRH-1 may be constitutively active, and suggests that signal transduction pathways leading to tumor 
development and proliferation also govern the activation of LRH-1 and associated GC synthesis. Of interest in this regard is that LRH-1 not only controls cell cycle progression, but that its activity is also controlled by the cell cycle [50]. Various mitogenic signals controlling tumor cell proliferation may therefore also promote the activation of LRH-1. In line with this idea is the observation that many colorectal tumors have activating mutations of the epidermal growth factor receptor pathway [113] and that epidermal growth factor can stimulate LRH-1 activation in an ERK1/2-dependent manner in Hela cells [95]. However, more detailed analysis of the signaling pathways leading to LRH-1 activation and GC synthesis in colorectal tumors will be required to confirm whether mitogenic stimuli are indeed important triggers of extra-adrenal GC synthesis in tumor cells.

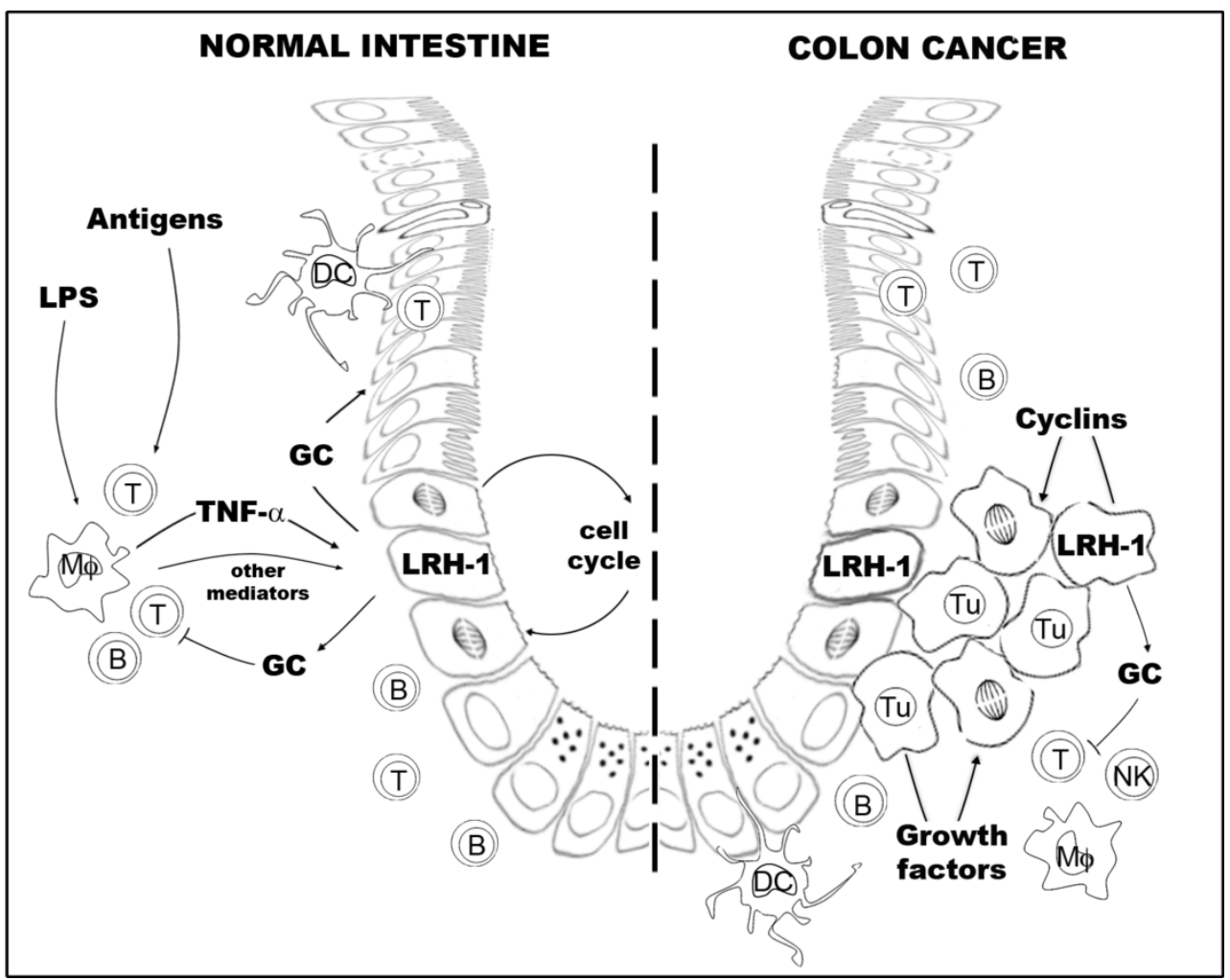

Abbreviations: B - B-Lymphocytes; DC - dendritic cells; LPS - lipopolysaccharides; $\mathrm{M} \varphi$ - macrophages; NK - natural killer cells; T - T-Lymphocytes; Tu - tumor cells.

Figure 2. Proposed role of intestinal GC synthesis in maintaining immune homeostasis in normal gut mucosa and promoting immune escape in colon cancer.

While the immunoregulatory role of GC synthesis in normal intestinal tissue is quite well established $[46,49,52,53]$, the evidence in colorectal tumors is yet relatively indirect. The supernatant of colorectal tumor cell lines and primary tumors has been found to contain a suppressive activity, which inhibits the activation of primary $\mathrm{T}$ cells, as measured by the 
induction of activation marker CD69 [55]. Similarly, tumor-derived supernatant was able to promote apoptosis in GC sensitive immune cells. Importantly, these suppressive or proapoptotic activities were blocked by either interfering with the GC synthesis pathway in tumor cells by metyrapone, or by blocking the GR in immune cells [55]. While colorectal tumor cells may also secrete other immunoregulatory factors, such as TGF $\beta$, these finding demonstrate that GC are present in the supernatant of tumor cells and that their concentration is high enough to promote biological responses and immunosuppression. The secretion of immunoregulatory GC by colorectal tumors may thus represent a novel mechanism how tumor cells escape from destruction by the immune system. Similar mechanisms may also exist in tumors from tissues capable of secreting bioactive GC, e.g. lung cancer.

\section{Conclusion}

In summary, the extremely potent GC synthesizing activity of the adrenal glands has obscured for a long time the fact that various other extra-adrenal tissues are important sources of immunoregulatory GC. This chapter has highlighted in particular the role of the pulmonary and intestinal mucosa, and its associated tumors, as potent sources of extraadrenal GC synthesis. Their more recent identification has lead to new interpretations of how locally produced GC may be involved in the maintenance of tissue homeostasis, regulation of inflammatory processes and tumor development. Finally, the detailed analysis of the differential signal transduction pathways controlling GC synthesis in the adrenals versus extra-adrenal tissues may offer novel opportunities for the development of therapeutic interventions.

\section{Author details}

Feodora I. Kostadinova and Thomas Brunner*

Division of Biochemical Pharmacology, Department of Biology, University of Konstanz, Germany

Nina Hostettler and Pamela Bianchi

Division of Experimental Pathology, Institute of Pathology, University of Bern, Switzerland

\section{Acknowledgement}

The authors thank previous and present members of the Brunner lab, especially Igor Cima, Mathias Müller, Mario Noti, Daniel Sidler and Nadia Corazza, for their contributions to the investigation of extra-adrenal GC synthesis, Kristina Schoonjans and Johan Auwerx for fruitful collaborations and many reagents, and the Swiss National Science Foundation, Swiss Cancer League, the Bangerter Foundation, the Crohn's and Colitis Foundation of America and the German Research Foundation for continuous support of this research area.

\footnotetext{
${ }^{*}$ Corresponding Author
} 


\section{References}

[1] Sapolsky RM, Romero LM, Munck AU (2000) How Do Glucocorticoids Influence Stress Responses? Integrating Permissive, Suppressive, Stimulatory, and Preparative Actions. Endocr Rev. 21: 55-89.

[2] Chrousos GP (1995) The Hypothalamic-Pituitary-Adrenal Axis and Immune-Mediated Inflammation. N Engl J Med. 332: 1351-62.

[3] Vacchio MS, Papadopoulos V, Ashwell JD (1994) Steroid Production in the Thymus: Implications for Thymocyte Selection. J Exp Med. 179: 1835-46.

[4] Lechner O, Wiegers GJ, Oliveira-Dos-Santos AJ, Dietrich H, Recheis H, et al. (2000) Glucocorticoid Production in the Murine Thymus. European journal of immunology. 30: 337-46.

[5] Pazirandeh A, Xue Y, Rafter I, Sjovall J, Jondal M, et al. (1999) Paracrine Glucocorticoid Activity Produced by Mouse Thymic Epithelial Cells. FASEB journal : official publication of the Federation of American Societies for Experimental Biology. 13: 893901.

[6] Ashwell JD, Lu FW, Vacchio MS (2000) Glucocorticoids in T Cell Development and Function*. Annu Rev Immunol. 18: 309-45.

[7] Taves MD, Gomez-Sanchez CE, Soma KK (2011) Extra-Adrenal Glucocorticoids and Mineralocorticoids: Evidence for Local Synthesis, Regulation, and Function. American journal of physiology. Endocrinology and metabolism. 301: E11-24.

[8] Slominski A, Ermak G, Mihm M (1996) Acth Receptor, Cyp11a1, Cyp17 and Cyp21a2 Genes Are Expressed in Skin. J Clin Endocrinol Metab. 81: 2746-9.

[9] Slominski A, Gomez-Sanchez CE, Foecking MF, Wortsman J (2000) Active Steroidogenesis in the Normal Rat Skin. Biochim Biophys Acta. 1474: 1-4.

[10] Slominski A, Wortsman J (2000) Neuroendocrinology of the Skin. Endocr Rev. 21: 45787.

[11] Slominski A, Wortsman J, Paus R, Elias PM, Tobin DJ, et al. (2008) Skin as an Endocrine Organ: Implications for Its Function. Drug Discov Today Dis Mech. 5: 137-44.

[12] Slominski A, Wortsman J, Pisarchik A, Zbytek B, Linton EA, et al. (2001) Cutaneous Expression of Corticotropin-Releasing Hormone (Crh), Urocortin, and Crh Receptors. FASEB journal : official publication of the Federation of American Societies for Experimental Biology. 15: 1678-93.

[13] Slominski A, Zbytek B, Szczesniewski A, Semak I, Kaminski J, et al. (2005) Crh Stimulation of Corticosteroids Production in Melanocytes Is Mediated by Acth. American journal of physiology. Endocrinology and metabolism. 288: E701-6.

[14] Slominski A, Zjawiony J, Wortsman J, Semak I, Stewart J, et al. (2004) A Novel Pathway for Sequential Transformation of 7-Dehydrocholesterol and Expression of the P450scc System in Mammalian Skin. Eur J Biochem. 271: 4178-88.

[15] Ito N, Ito T, Kromminga A, Bettermann A, Takigawa M, et al. (2005) Human Hair Follicles Display a Functional Equivalent of the Hypothalamic-Pituitary-Adrenal Axis and Synthesize Cortisol. FASEB journal : official publication of the Federation of American Societies for Experimental Biology. 19: 1332-4. 
[16] Paus R, Botchkarev VA, Botchkareva NV, Mecklenburg L, Luger T, et al. (1999) The Skin Pomc System (Sps). Leads and Lessons from the Hair Follicle. Annals of the New York Academy of Sciences. 885: 350-63.

[17] Paus R, Ito N, Takigawa M, Ito T (2003) The Hair Follicle and Immune Privilege. J Investig Dermatol Symp Proc. 8: 188-94.

[18] Thiboutot D, Jabara S, McAllister JM, Sivarajah A, Gilliland K, et al. (2003) Human Skin Is a Steroidogenic Tissue: Steroidogenic Enzymes and Cofactors Are Expressed in Epidermis, Normal Sebocytes, and an Immortalized Sebocyte Cell Line (Seb-1). J Invest Dermatol. 120: 905-14.

[19] Vukelic S, Stojadinovic O, Pastar I, Rabach M, Krzyzanowska A, et al. (2011) Cortisol Synthesis in Epidermis Is Induced by Il-1 and Tissue Injury. The Journal of biological chemistry. 286: 10265-75.

[20] Casal AJ, Silvestre JS, Delcayre C, Capponi AM (2003) Expression and Modulation of Steroidogenic Acute Regulatory Protein Messenger Ribonucleic Acid in Rat Cardiocytes and after Myocardial Infarction. Endocrinology. 144: 1861-8.

[21] Silvestre JS, Robert V, Heymes C, Aupetit-Faisant B, Mouas C, et al. (1998) Myocardial Production of Aldosterone and Corticosterone in the Rat. Physiological Regulation. The Journal of biological chemistry. 273: 4883-91.

[22] Silvestre JS, Heymes C, Oubenaissa A, Robert V, Aupetit-Faisant B, et al. (1999) Activation of Cardiac Aldosterone Production in Rat Myocardial Infarction: Effect of Angiotensin Ii Receptor Blockade and Role in Cardiac Fibrosis. Circulation. 99: 2694701.

[23] Takeda Y, Miyamori I, Yoneda T, Iki K, Hatakeyama H, et al. (1994) Synthesis of Corticosterone in the Vascular Wall. Endocrinology. 135: 2283-6.

[24] Takeda Y, Miyamori I, Yoneda T, Hatakeyama H, Inaba S, et al. (1996) Regulation of Aldosterone Synthase in Human Vascular Endothelial Cells by Angiotensin Ii and Adrenocorticotropin. J Clin Endocrinol Metab. 81: 2797-800.

[25] Takeda Y (2005) Role of Cardiovascular Aldosterone in Hypertension. Curr Med Chem Cardiovasc Hematol Agents. 3: 261-6.

[26] Hatakeyama H, Miyamori I, Takeda Y, Yamamoto H, Mabuchi H (1996) The Expression of Steroidogenic Enzyme Genes in Human Vascular Cells. Biochem Mol Biol Int. 40: 639-45.

[27] Kayes-Wandover KM, White PC (2000) Steroidogenic Enzyme Gene Expression in the Human Heart. J Clin Endocrinol Metab. 85: 2519-25.

[28] Young MJ, Clyne CD, Cole TJ, Funder JW (2001) Cardiac Steroidogenesis in the Normal and Failing Heart. J Clin Endocrinol Metab. 86: 5121-6.

[29] Ahmad N, Romero DG, Gomez-Sanchez EP, Gomez-Sanchez CE (2004) Do Human Vascular Endothelial Cells Produce Aldosterone? Endocrinology. 145: 3626-9.

[30] Baulieu EE (1998) Neurosteroids: A Novel Function of the Brain. Psychoneuroendocrinology. 23: 963-87.

[31] Mellon SH (2007) Neurosteroid Regulation of Central Nervous System Development. Pharmacol Ther. 116: 107-24. 
[32] Gunn BG, Brown AR, Lambert JJ, Belelli D (2011) Neurosteroids and Gaba(a) Receptor Interactions: A Focus on Stress. Front Neurosci. 5: 131.

[33] Stromstedt M, Waterman MR (1995) Messenger Rnas Encoding Steroidogenic Enzymes Are Expressed in Rodent Brain. Brain Res Mol Brain Res. 34: 75-88.

[34] MacKenzie SM, Clark CJ, Ingram MC, Lai M, Seckl J, et al. (2000) Corticosteroid Production by Fetal Rat Hippocampal Neurons. Endocr Res. 26: 531-5.

[35] MacKenzie SM, Clark CJ, Fraser R, Gomez-Sanchez CE, Connell JM, et al. (2000) Expression of 11beta-Hydroxylase and Aldosterone Synthase Genes in the Rat Brain. J Mol Endocrinol. 24: 321-8.

[36] Yu L, Romero DG, Gomez-Sanchez CE, Gomez-Sanchez EP (2002) Steroidogenic Enzyme Gene Expression in the Human Brain. Mol Cell Endocrinol. 190: 9-17.

[37] Higo S, Hojo Y, Ishii H, Komatsuzaki Y, Ooishi Y, et al. (2011) Endogenous Synthesis of Corticosteroids in the Hippocampus. PLoS One. 6: e21631.

[38] Basu R, Singh RJ, Basu A, Chittilapilly EG, Johnson CM, et al. (2004) Splanchnic Cortisol Production Occurs in Humans: Evidence for Conversion of Cortisone to Cortisol Via the 11-Beta Hydroxysteroid Dehydrogenase (11beta-Hsd) Type 1 Pathway. Diabetes. 53: 2051-9.

[39] Andrew R, Westerbacka J, Wahren J, Yki-Jarvinen H, Walker BR (2005) The Contribution of Visceral Adipose Tissue to Splanchnic Cortisol Production in Healthy Humans. Diabetes. 54: 1364-70.

[40] Harris HJ, Kotelevtsev Y, Mullins JJ, Seckl JR, Holmes MC (2001) Intracellular Regeneration of Glucocorticoids by 11beta-Hydroxysteroid Dehydrogenase (11betaHsd)-1 Plays a Key Role in Regulation of the Hypothalamic-Pituitary-Adrenal Axis: Analysis of 11beta-Hsd-1-Deficient Mice. Endocrinology. 142: 114-20.

[41] Carter RN, Paterson JM, Tworowska U, Stenvers DJ, Mullins JJ, et al. (2009) Hypothalamic-Pituitary-Adrenal Axis Abnormalities in Response to Deletion of 11betaHsd1 Is Strain-Dependent. J Neuroendocrinol. 21: 879-87.

[42] Wyrwoll CS, Holmes MC, Seckl JR (2011) 11beta-Hydroxysteroid Dehydrogenases and the Brain: From Zero to Hero, a Decade of Progress. Front Neuroendocrinol. 32: 265-86.

[43] Holmes MC, Carter RN, Noble J, Chitnis S, Dutia A, et al. (2010) 11beta-Hydroxysteroid Dehydrogenase Type 1 Expression Is Increased in the Aged Mouse Hippocampus and Parietal Cortex and Causes Memory Impairments. J Neurosci. 30: 6916-20.

[44] Sandeep TC, Yau JL, MacLullich AM, Noble J, Deary IJ, et al. (2004) 11betaHydroxysteroid Dehydrogenase Inhibition Improves Cognitive Function in Healthy Elderly Men and Type 2 Diabetics. Proceedings of the National Academy of Sciences of the United States of America. 101: 6734-9.

[45] MacLullich AM, Ferguson KJ, Reid LM, Deary IJ, Starr JM, et al. (2012) 11betaHydroxysteroid Dehydrogenase Type 1, Brain Atrophy and Cognitive Decline. Neurobiol Aging. 33: 207 e1-8.

[46] Cima I, Corazza N, Dick B, Fuhrer A, Herren S, et al. (2004) Intestinal Epithelial Cells Synthesize Glucocorticoids and Regulate T Cell Activation. The Journal of experimental medicine. 200: 1635-46. 
[47] Mueller M, Atanasov A, Cima I, Corazza N, Schoonjans K, et al. (2007) Differential Regulation of Glucocorticoid Synthesis in Murine Intestinal Epithelial Versus Adrenocortical Cell Lines. Endocrinology. 148: 1445-53.

[48] Mueller M, Cima I, Noti M, Fuhrer A, Jakob S, et al. (2006) The Nuclear Receptor Lrh-1 Critically Regulates Extra-Adrenal Glucocorticoid Synthesis in the Intestine. The Journal of experimental medicine. 203: 2057-62.

[49] Coste A, Dubuquoy L, Barnouin R, Annicotte JS, Magnier B, et al. (2007) Lrh-1Mediated Glucocorticoid Synthesis in Enterocytes Protects against Inflammatory Bowel Disease. Proc Natl Acad Sci U S A. 104: 13098-103.

[50] Atanasov AG, Leiser D, Roesselet C, Noti M, Corazza N, et al. (2008) Cell CycleDependent Regulation of Extra-Adrenal Glucocorticoid Synthesis in Murine Intestinal Epithelial Cells. FASEB journal : official publication of the Federation of American Societies for Experimental Biology. 22: 4117-25.

[51] Noti M, Sidler D, Brunner T (2009) Extra-Adrenal Glucocorticoid Synthesis in the Intestinal Epithelium: More Than a Drop in the Ocean? Semin Immunopathol. 31: 23748.

[52] Noti M, Corazza N, Tuffin G, Schoonjans K, Brunner T (2010) Lipopolysaccharide Induces Intestinal Glucocorticoid Synthesis in a Tnfalpha-Dependent Manner. FASEB journal : official publication of the Federation of American Societies for Experimental Biology. 24: 1340-6.

[53] Noti M, Corazza N, Mueller C, Berger B, Brunner T (2010) Tnf Suppresses Acute Intestinal Inflammation by Inducing Local Glucocorticoid Synthesis. The Journal of experimental medicine. 207: 1057-66.

[54] Hostettler N, Bianchi P, Gennari-Moser C, Kassahn D, Schoonjans K, et al. (2012) Local Glucocorticoid Production in the Mouse Lung Is Induced by Immune Cell Stimulation. Allergy. 67: 227-34.

[55] Sidler D, Renzulli P, Schnoz C, Berger B, Schneider-Jakob S, et al. (2011) Colon Cancer Cells Produce Immunoregulatory Glucocorticoids. Oncogene. 30: 2411-9.

[56] Keeney DS, Jenkins CM, Waterman MR (1995) Developmentally Regulated Expression of Adrenal 17 Alpha-Hydroxylase Cytochrome P450 in the Mouse Embryo. Endocrinology. 136: 4872-9.

[57] Okamoto M, Nonaka Y, Takemori H, Doi J (2005) Molecular Identity and Gene Expression of Aldosterone Synthase Cytochrome P450. Biochem Biophys Res Commun. 338: 325-30.

[58] Laurent V, Kimble A, Peng B, Zhu P, Pintar JE, et al. (2002) Mortality in 7b2 Null Mice Can Be Rescued by Adrenalectomy: Involvement of Dopamine in Acth Hypersecretion. Proceedings of the National Academy of Sciences of the United States of America. 99: 3087-92.

[59] Davies E, MacKenzie SM (2003) Extra-Adrenal Production of Corticosteroids. Clin Exp Pharmacol Physiol. 30: 437-45.

[60] Blackburn CC, Manley NR (2004) Developing a New Paradigm for Thymus Organogenesis. Nat Rev Immunol. 4: 278-89. 
[61] Spits H (2002) Development of Alphabeta T Cells in the Human Thymus. Nat Rev Immunol. 2: 760-72.

[62] Ashwell JD, Vacchio MS, Galon J (2000) Do Glucocorticoids Participate in Thymocyte Development? Immunol Today. 21: 644-6.

[63] Godfrey DI, Purton JF, Boyd RL, Cole TJ (2000) Stress-Free T-Cell Development: Glucocorticoids Are Not Obligatory. Immunol Today. 21: 606-11.

[64] Zacharchuk CM, Mercep M, Chakraborti PK, Simons SS, Jr., Ashwell JD (1990) Programmed T Lymphocyte Death. Cell Activation- and Steroid-Induced Pathways Are Mutually Antagonistic. Journal of immunology. 145: 4037-45.

[65] Kupper TS, Fuhlbrigge RC (2004) Immune Surveillance in the Skin: Mechanisms and Clinical Consequences. Nat Rev Immunol. 4: 211-22.

[66] Rousseau K, Kauser S, Pritchard LE, Warhurst A, Oliver RL, et al. (2007) Proopiomelanocortin (Pomc), the Acth/Melanocortin Precursor, Is Secreted by Human Epidermal Keratinocytes and Melanocytes and Stimulates Melanogenesis. FASEB journal : official publication of the Federation of American Societies for Experimental Biology. 21: 1844-56.

[67] Slominski A, Zbytek B, Semak I, Sweatman T, Wortsman J (2005) Crh Stimulates Pomc Activity and Corticosterone Production in Dermal Fibroblasts. J Neuroimmunol. 162: 97-102.

[68] Mellon SH, Griffin LD (2002) Neurosteroids: Biochemistry and Clinical Significance. Trends Endocrinol Metab. 13: 35-43.

[69] Kishimoto W, Hiroi T, Shiraishi M, Osada M, Imaoka S, et al. (2004) Cytochrome P450 2d Catalyze Steroid 21-Hydroxylation in the Brain. Endocrinology. 145: 699-705.

[70] Ye P, Kenyon CJ, Mackenzie SM, Nichol K, Seckl JR, et al. (2008) Effects of Acth, Dexamethasone, and Adrenalectomy on 11beta-Hydroxylase (Cyp11b1) and Aldosterone Synthase (Cyp11b2) Gene Expression in the Rat Central Nervous System. J Endocrinol. 196: 305-11.

[71] Walker BR, Andrew R (2006) Tissue Production of Cortisol by 11beta-Hydroxysteroid Dehydrogenase Type 1 and Metabolic Disease. Annals of the New York Academy of Sciences. 1083: 165-84.

[72] Yau JL, McNair KM, Noble J, Brownstein D, Hibberd C, et al. (2007) Enhanced Hippocampal Long-Term Potentiation and Spatial Learning in Aged 11betaHydroxysteroid Dehydrogenase Type 1 Knock-out Mice. J Neurosci. 27: 10487-96.

[73] Takeda Y, Miyamori I, Yoneda T, Iki K, Hatakeyama H, et al. (1995) Production of Aldosterone in Isolated Rat Blood Vessels. Hypertension. 25: 170-3.

[74] Christy C, Hadoke PW, Paterson JM, Mullins JJ, Seckl JR, et al. (2003) 11betaHydroxysteroid Dehydrogenase Type 2 in Mouse Aorta: Localization and Influence on Response to Glucocorticoids. Hypertension. 42: 580-7.

[75] Hadoke PW, Macdonald L, Logie JJ, Small GR, Dover AR, et al. (2006) Intra-Vascular Glucocorticoid Metabolism as a Modulator of Vascular Structure and Function. Cellular and molecular life sciences : CMLS. 63: 565-78.

[76] Goodyer CG, Branchaud CL (1981) Regulation of Hormone Production in the Human Feto-Placental Unit. Ciba Found Symp. 86: 89-123. 
[77] Yong PY, Thong KJ, Andrew R, Walker BR, Hillier SG (2000) Development-Related Increase in Cortisol Biosynthesis by Human Granulosa Cells. J Clin Endocrinol Metab. 85: 4728-33.

[78] Wang GM, Ge RS, Latif SA, Morris DJ, Hardy MP (2002) Expression of 11betaHydroxylase in Rat Leydig Cells. Endocrinology. 143: 621-6.

[79] Burton PJ, Krozowski ZS, Waddell BJ (1998) Immunolocalization of 11betaHydroxysteroid Dehydrogenase Types 1 and 2 in Rat Uterus: Variation across the Estrous Cycle and Regulation by Estrogen and Progesterone. Endocrinology. 139: 37682.

[80] Quirk SJ, Slattery J, Funder JW (1990) 11 Beta-Hydroxysteroid Dehydrogenase Activity in the Mammary Gland. J Steroid Biochem. 35: 623-5.

[81] Brunner T (2009) Living on the Edge: Immune Cells and Immunopathology in the Intestinal Mucosa. Seminars in immunopathology. 31: 143-4.

[82] Keeney DS, Ikeda Y, Waterman MR, Parker KL (1995) Cholesterol Side-Chain Cleavage Cytochrome P450 Gene Expression in the Primitive Gut of the Mouse Embryo Does Not Require Steroidogenic Factor 1. Mol Endocrinol. 9: 1091-8.

[83] Sadovsky Y, Crawford PA, Woodson KG, Polish JA, Clements MA, et al. (1995) Mice Deficient in the Orphan Receptor Steroidogenic Factor 1 Lack Adrenal Glands and Gonads but Express P450 Side-Chain-Cleavage Enzyme in the Placenta and Have Normal Embryonic Serum Levels of Corticosteroids. Proceedings of the National Academy of Sciences of the United States of America. 92: 10939-43.

[84] Brunner T, Arnold D, Wasem C, Herren S, Frutschi C (2001) Regulation of Cell Death and Survival in Intestinal Intraepithelial Lymphocytes. Cell death and differentiation. 8: 706-14.

[85] Wasem C, Arnold D, Saurer L, Corazza N, Jakob S, et al. (2003) Sensitizing AntigenSpecific Cd8+ T Cells for Accelerated Suicide Causes Immune Incompetence. The Journal of clinical investigation. 111: 1191-9.

[86] Corazza N, Muller S, Brunner T, Kagi D, Mueller C (2000) Differential Contribution of Fas- and Perforin-Mediated Mechanisms to the Cell-Mediated Cytotoxic Activity of Naive and in Vivo-Primed Intestinal Intraepithelial Lymphocytes. Journal of immunology. 164: 398-403.

[87] Parker KL, Rice DA, Lala DS, Ikeda Y, Luo X, et al. (2002) Steroidogenic Factor 1: An Essential Mediator of Endocrine Development. Recent Prog Horm Res. 57: 19-36.

[88] Parker KL (1998) The Roles of Steroidogenic Factor 1 in Endocrine Development and Function. Mol Cell Endocrinol. 145: 15-20.

[89] Fayard E, Auwerx J, Schoonjans K (2004) Lrh-1: An Orphan Nuclear Receptor Involved in Development, Metabolism and Steroidogenesis. Trends Cell Biol. 14: 250-60.

[90] Sirianni R, Seely JB, Attia G, Stocco DM, Carr BR, et al. (2002) Liver Receptor Homologue-1 Is Expressed in Human Steroidogenic Tissues and Activates Transcription of Genes Encoding Steroidogenic Enzymes. J Endocrinol. 174: R13-7.

[91] Wu YG, Bennett J, Talla D, Stocco C (2011) Testosterone, Not 5alphaDihydrotestosterone, Stimulates Lrh-1 Leading to Fsh-Independent Expression of Cyp19 and P450scc in Granulosa Cells. Mol Endocrinol. 25: 656-68. 
[92] Suzawa M, Ingraham HA (2008) The Herbicide Atrazine Activates Endocrine Gene Networks Via Non-Steroidal Nr5a Nuclear Receptors in Fish and Mammalian Cells. PLoS One. 3: e2117.

[93] Whitby RJ, Stec J, Blind RD, Dixon S, Leesnitzer LM, et al. (2011) Small Molecule Agonists of the Orphan Nuclear Receptors Steroidogenic Factor-1 (Sf-1, Nr5a1) and Liver Receptor Homologue-1 (Lrh-1, Nr5a2). J Med Chem. 54: 2266-81.

[94] Sablin EP, Krylova IN, Fletterick RJ, Ingraham HA (2003) Structural Basis for LigandIndependent Activation of the Orphan Nuclear Receptor Lrh-1. Molecular cell. 11: 157585.

[95] Lee YK, Choi YH, Chua S, Park YJ, Moore DD (2006) Phosphorylation of the Hinge Domain of the Nuclear Hormone Receptor Lrh-1 Stimulates Transactivation. The Journal of biological chemistry. 281: 7850-5.

[96] Sablin EP, Woods A, Krylova IN, Hwang P, Ingraham HA, et al. (2008) The Structure of Corepressor Dax-1 Bound to Its Target Nuclear Receptor Lrh-1. Proceedings of the National Academy of Sciences of the United States of America. 105: 18390-5.

[97] Lee YK, Moore DD (2002) Dual Mechanisms for Repression of the Monomeric Orphan Receptor Liver Receptor Homologous Protein-1 by the Orphan Small Heterodimer Partner. The Journal of biological chemistry. 277: 2463-7.

[98] Reimund JM, Wittersheim C, Dumont S, Muller CD, Baumann R, et al. (1996) Mucosal Inflammatory Cytokine Production by Intestinal Biopsies in Patients with Ulcerative Colitis and Crohn's Disease. J Clin Immunol. 16: 144-50.

[99] Rutgeerts PJ (1999) Review Article: Efficacy of Infliximab in Crohn's Disease--Induction and Maintenance of Remission. Aliment Pharmacol Ther. 13 Suppl 4: 9-15; discussion 38.

[100] Ford AC, Sandborn WJ, Khan KJ, Hanauer SB, Talley NJ, et al. (2011) Efficacy of Biological Therapies in Inflammatory Bowel Disease: Systematic Review and MetaAnalysis. Am J Gastroenterol. 106: 644-59, quiz 60.

[101] Provost PR, Tremblay Y (2005) Genes Involved in the Adrenal Pathway of Glucocorticoid Synthesis Are Transiently Expressed in the Developing Lung. Endocrinology. 146: 2239-45.

[102] Sampath-Kumar R, Yu M, Khalil MW, Yang K (1997) Metyrapone Is a Competitive Inhibitor of 11beta-Hydroxysteroid Dehydrogenase Type 1 Reductase. J Steroid Biochem Mol Biol. 62: 195-9.

[103] Roteli-Martins C, Naud P, De Borba P, Teixeira J, De Carvalho N, et al. (2012) Sustained Immunogenicity and Efficacy of the Hpv-16/18 As04-Adjuvanted Vaccine: Up to 8.4 Years of Follow-Up. Hum Vaccin Immunother. 8.

[104] Lehtinen M, Paavonen J, Wheeler CM, Jaisamrarn U, Garland SM, et al. (2012) Overall Efficacy of Hpv-16/18 As04-Adjuvanted Vaccine against Grade 3 or Greater Cervical Intraepithelial Neoplasia: 4-Year End-of-Study Analysis of the Randomised, DoubleBlind Patricia Trial. Lancet Oncol. 13: 89-99.

[105] Galon J, Costes A, Sanchez-Cabo F, Kirilovsky A, Mlecnik B, et al. (2006) Type, Density, and Location of Immune Cells within Human Colorectal Tumors Predict Clinical Outcome. Science. 313: 1960-4. 
[106] Newell-Price J, Bertagna X, Grossman AB, Nieman LK (2006) Cushing's Syndrome. Lancet. 367: 1605-17.

[107] Isidori AM, Kaltsas GA, Pozza C, Frajese V, Newell-Price J, et al. (2006) The Ectopic Adrenocorticotropin Syndrome: Clinical Features, Diagnosis, Management, and LongTerm Follow-Up. J Clin Endocrinol Metab. 91: 371-7.

[108] Shahani S, Nudelman RJ, Nalini R, Kim HS, Samson SL (2010) Ectopic CorticotropinReleasing Hormone (Crh) Syndrome from Metastatic Small Cell Carcinoma: A Case Report and Review of the Literature. Diagn Pathol. 5: 56.

[109] Botrugno OA, Fayard E, Annicotte JS, Haby C, Brennan T, et al. (2004) Synergy between Lrh-1 and Beta-Catenin Induces G1 Cyclin-Mediated Cell Proliferation. Molecular cell. 15: 499-509.

[110] Fernandez-Marcos PJ, Auwerx J, Schoonjans K (2011) Emerging Actions of the Nuclear Receptor Lrh-1 in the Gut. Biochim Biophys Acta. 1812: 947-55.

[111] Schoonjans K, Dubuquoy L, Mebis J, Fayard E, Wendling O, et al. (2005) Liver Receptor Homolog 1 Contributes to Intestinal Tumor Formation through Effects on Cell Cycle and Inflammation. Proceedings of the National Academy of Sciences of the United States of America. 102: 2058-62.

[112] Benod C, Vinogradova MV, Jouravel N, Kim GE, Fletterick RJ, et al. (2011) Nuclear Receptor Liver Receptor Homologue 1 (Lrh-1) Regulates Pancreatic Cancer Cell Growth and Proliferation. Proceedings of the National Academy of Sciences of the United States of America. 108: 16927-31.

[113] Normanno N, Tejpar S, Morgillo F, De Luca A, Van Cutsem E, et al. (2009) Implications for Kras Status and Egfr-Targeted Therapies in Metastatic Crc. Nat Rev Clin Oncol. 6: 519-27. 